\title{
Space tourism: prospects, positioning, and planning
}

\section{Sam Cole}

Sam Cole is a Professor at the Department of Urban and Regional Planning, University at Buffalo, Buffalo, New York, USA.
(C) Sam Cole. Published in the Journal of Tourism Futures.

This article is published under the Creative Commons Attribution (CC BY 4.0) licence. Anyone may reproduce, distribute, translate and create derivative works of this article (for both commercial and non-commercial purposes), subject to full attribution to the original publication and authors. The full terms of this licence may be seen at: http://creativecommons.org/ licences/by/4.0/legalcode

\begin{abstract}
Purpose - The purpose of this paper is to explain how the elements of a tourism policy class (historical, structural, economic, social, and technological) are employed in the discussion and analysis of space tourism.

Design/methodology/approach - The material serves as revision class of methods and concepts. The topics and methods covered depend in part on previous class content making use of space tourism materials available on the web and in the literature.

Findings - The sources cited cover a remarkable and growing range of space tourism endeavors worldwide. Whilst it is definitively not a forecast, the paper does appraise future directions in space tourism. Practical implications - Further research is required in order to properly evaluate the value of space tourism to future human societies, and strategize accordingly.

Originality/value - As a source-based review, the paper has limited originality, but shows the possibilities and limitations of tourism planning methods for space tourism.

Keywords Tourism, Forecasting, Tourism policy, Space, Economic impact analysis, Teaching and learning, Future studies, Tourism planning methods

Paper type Viewpoint

\section{Introduction}

As material for a slightly tongue in cheek revision class for a tourism policy course, my paper serves primarily as a reminder of the concepts and methods to be used in students' term projects. The course itself similarly revises and applies methods from previous courses. Here, it should be said that methods used in tourism planning practice are considerably less exotic than the subject of space tourism, while the subject itself shows the power and importance of imagination, and by extension futures thinking in general. Tourism and the study of tourism has become explicitly such a multi-dimensional field where globalization directly confronts locality and identity. However, it is a field in which future defies history, futurism confronts tradition, unprecedented wealth co-exists with abject poverty, and imagination bends reality. For these reasons the study of tourism begs insights from many disciplines and illustrates many of the challenges for planning and policy.
\end{abstract}

\section{Where to begin?}

Students from planning programs typically enter city and county-level planning departments that increasingly incorporate tourism promotion and development as a cornerstone of their activities. Methods in planning practice are relatively pragmatic and heuristic, unless some dubious policy or investment is to be advanced. The course aims to provide students with a supplementary grounding in heuristics such as Butler (1980) and Plog (2001). Students' final projects typically devise and detail aspects of a tourism strategy for some exotic destination or an exotic development in a familiar location, addressing economic, cultural, social, and 
ecological aspects of a tourism strategy. This course segment had its origins with a student who insisted on covering space tourism for his final project!

There are several starting points for thinking about space tourism for planning students: science fiction and science, defense in space, space tourism speculation, actual space tourists, or currently planned space tourism projects. Beyond a vehicle for revising tourism planning methods and indulging my own fantasies, the most important rationale for introducing the topic of space tourism into a tourism planning course is simply that space travel fiction has (almost) become fact. Since the industry is forecast to become a driver of the global economy and space tourism ports have been proposed for a number of island and rural locations, it is also possible, even likely, that some current students could be involved in some aspects of space tourism planning. Already research has left the solar system and there are currently five satellites from Earth around Mars. In the Americas alone, space tourism bases are planned for the Nevada desert, and others are under negotiation for the Caribbean islands of Puerto Rico and Curacao.

A useful starting point is the growing technical, specialist, and other literature on the prospects for space tourism. This covers a broad range of topics with the most current available on the web. There are a goodly number of books and technical reports, but not yet a dedicated "Journal of Space Tourism" but this can only be a matter of time. There is already a "Space Futures Journal" on the Space Futures web site. A selection of these publications and web sites dealing with aspects of space travel from craft design, health, accommodation, and other topics are referred to throughout this review. These web sites have over-lapping, complementary, and sometimes contradictory information. In some cases, the sources are more topical or more detailed and less or more cautious about the challenges and prospects. For example, the first flight from the relatively small Caribbean island of Curacao will be carried out in 2016 by Space Expedition Corporation with the Lynx.

There are also several articles in the tourism literature, for example, Crouch (2001), in "The Market for Space Tourism: Early Indications" reviewed the hurdles facing the development and growth of space tourism, not least of which was simply making "credible and reliable estimates of market demand." He identified several research challenges and methodological alternatives to improve research findings. Coincidentally, Crouch's article coincided with the first tourist in space. Patrick Collins $(2000,2014)$ appears to be the most consistently cited space-tourism analyst and proponent of space tourism development, and his recent (May, 2014) video presentation updates this material and makes the strongest case for space tourism (Collins, 2000, 2014). The most comprehensive web site, SpaceTourism.com, is an excellent on-line tutorial on space tourism that appears to draw liberally on Collin's work, as I do in my tourism course review. The SpaceTourism.com site lists "some key documents from the archive to get you started": First, what the growth of a space tourism industry could contribute to employment, economic growth, environmental protection, education, culture and world peace. Second, space tourism market demand and the transportation infrastructure. Third, general public space travel and tourism. Fourth, artificial gravity and the architecture of orbital habitats. Fifth, prospects of space tourism.

\section{Space, stars, and status - marketing and positioning space tourism}

In 2001 the world's first space tourist, American Dennis Tito, travelled on a Russian Soyuz rocket to the International Space Station, as did the second, South African Mark Shuttleworth, and the third, Greg Olsen, in 2005, and also Charles Simonyi in 2007 and 2009. As wealthy businessmen, they could afford the $\$ 20-35$ million (about half what NASA currently pays Russia for its own astronauts). International recording artist, Sarah Brightman, is slated to be the first female space tourist in 2015. In view of the astronomical cost of their trips, counting these space travelers as "tourists" may be a stretch. Nonetheless they are the acknowledged pioneers. Well before this, in 1964, Gerhard Pistor, an Austrian journalist, walked into a Vienna travel agency and asked for a booking on the Pan American World Airways first flight to the moon. By 1989, 20 years after man first set foot on the lunar surface, Pan Am had more than 93,000 wait-listed for the airline's first passenger flight to the moon, sadly preempted by the airline's cash-strapped demise in 1991! (Sun Sentinel September 3, 1989). Nonetheless, the latent demand was clear.

PAGE 132 | JOURNAL OF TOURISM FUTURES $\mid$ VOL. 1 NO. 22015 
SpaceTourism.com sees "an enormous unsatisfied demand for space travel [...] market research has revealed that most people, at least in the industrialized countries, would like to take a trip to space if it was possible." They explain that "Space Tourism is the term that's come to be used to mean ordinary members of the public buying tickets to travel to space and back. Many people find this idea futuristic. But over the past few years a growing volume of professional work has been done on the subject, and it's now clear that setting up commercial space tourism services is a realistic target for business today." And the reasons why it is going to happen this time include that "people want it, it's a realistic objective, it's the only way in which space activities can become profitable, it's the quickest way to start to use the limitless resources of space to solve our problems on Earth, living in space involves every line of business, from construction to marketing, fashion, interior-design and law, and not least, because it will be fun!" Box 1 illustrates some of the space tourism stories to be found on the web.

The 2013 Virtuoso Life $®$ "Travel Dreams" pitch for space travel epitomizes tourist marketing hype: "At Park Avenue Travel we help create your dream vacation. We can tailor your trip to provide a unique, unforgettable experience. We believe that travel should be a journey, not just a destination! Virgin Galactic's sub-orbital space trips promise to be the most intense and wonderful experiences that passengers have ever had. Astronauts of the past 45 years have all returned to earth struggling to convey the enormity of what they have discovered and with their perceptions clearly changed. To be able to extend that privilege to people from all walks of life has been a long held ambition at Virgin."

Despite that flights initially scheduled to begin in 2009 were repeatedly postponed, by 2012 more than 200 tickets had been sold. Seat numbers 1-100 costing US $\$ 200,000$ are sold out, as are the similarly-priced 101-199, 200-299, and 300-399 rides. "Call 1-800-220-TRIP to reserve your ticket today"!! They are not alone in the space tourism promotion universe: HowStuffWorks.com encourages us to "Make your reservations now. The space tourism industry is officially open for business, and tickets are going for a mere $\$ 20$ million for a one-week stay in space." Richard Branson cited in "Tough day' for space travel as Virgin Galactic's spaceship crashes" says over 700 seats are now reserved. But as Encyclopedia Astronautica observes, few can afford the $\$ 20$ million or the trip to the Mir space station and so far there are no

\section{Box 1. Annotated adventures in space}

Xcor Aerospace is counting down to 2010 (or coming soon)

The two-seater tourist Lynx rocket ship will blast toward the sky at 1,500 miles per hour - The pilot cuts the engines three minutes in and lets momentum carry the Lynx to its peak altitude of 200,000 feet commercial jets top out around 30,000 feet - drifting for a moment, the passenger can see the blue curve of Earth's atmosphere fade into the black void of space - Then, gravity tugs the plane back toward reentry - The round trip will only take 30 minutes.

First hotel on the moon finally opens August 23, 2025

Today a new chapter in space tourism was written. Rod Markham and his wife-to-be Susan Millster arrived safely on the moon to spend five days as the first guests at the Starbright Hotel. The record price was US\$ 3.7 million per night, per person (inclusive of transfer from earth). The hotel has so far no employees, only temporary staff. There is no room service, or bathroom and guests clean their own room. They were accompanied by six other astronauts to set up further accommodation for guests with reservations next year.

First tourist heading for Mars September 21, 2050

The first tourist heading for Mars will be the 38-year-old US businessman Patrick Clifford in June 2052, together with the other six astronauts. The trip involves two years of training, for a five months at a cost of US\$1.3 billion.

Annotated from: features.csmonitor.com/innovation/2008/06/26/space-tourism-is-ready-for-takeoff/; www.newsoffuture.com/first_hotel_on_the_moon_space_tourism.html; p10.hostingprod.com/@ www.newsoffuture.com/first_tourist_heading_for_mars_space_tourism.html 
takers for the Russian offer to take a trip around the moon for $\$ 100$ million. In contrast, pre-marketing of sub-orbital rides suggests there are thousands willing and able to pay the $\$ 100,000-\$ 200,000$ for a few minutes weightlessness with view of the earth as a planet. But, they say, "Orbital tourism is another matter."

Surveys of the potential market for space travel began well in advance of its arrival. Indeed, the first space-tourism market research was undertaken in Japan in 1993 showed "extremely positive" results: some 70 percent of respondents would like to travel to space, and almost half would pay three months' salary to do so. Soon after, in 1995, nation-wide telephone surveys in Canada and USA found that "the idea of space tourism is massively popular." In 1997 the US "National Leisure Travel Monitor" survey included questions on space tourism for the first time. Of 1,500 Americans surveyed, 42 percent were interested in a space cruise, and were willing to spend an average of $\$ 10,800$ for the trip. These findings are very similar to those for Japan.

There is an inevitable overlap between age, income, and geography, with the greatest interest 20-40-year-olds. The published surveys do not show how this latent demand for space travel in the USA and elsewhere varies across the income spectrum, but like other forms of high-end, very expensive recreation, one factor driving demand has to be shift in national and global income distribution. In the USA and several other counties, including emerging markets such as Russia and China, the income of richer top few percent of households has risen at an unprecedented rate, creating the necessary discretionary income for the target market.

It will be interesting to observe (say, by the year 2100) how space destinations correspond to Plog's (2001) useful heuristic - expressing how the distribution visitors' personalities along a psychometric spectrum (from very cautious and conventional to risk-taking and adventuresome) overlays the positioning of destination. It represents a cross-section of destinations at a given point in time, whereby destinations (and visitors too) transform as they age. A speculative illustration is given in Figure 1. Jules Verne's space tourism pioneers would be Plog's "venturers." At some point in the future, these same personality types will be surfing Jupiter's moonbeams.

Figure 1 A psychometric mapping of space tourism destinations and activities

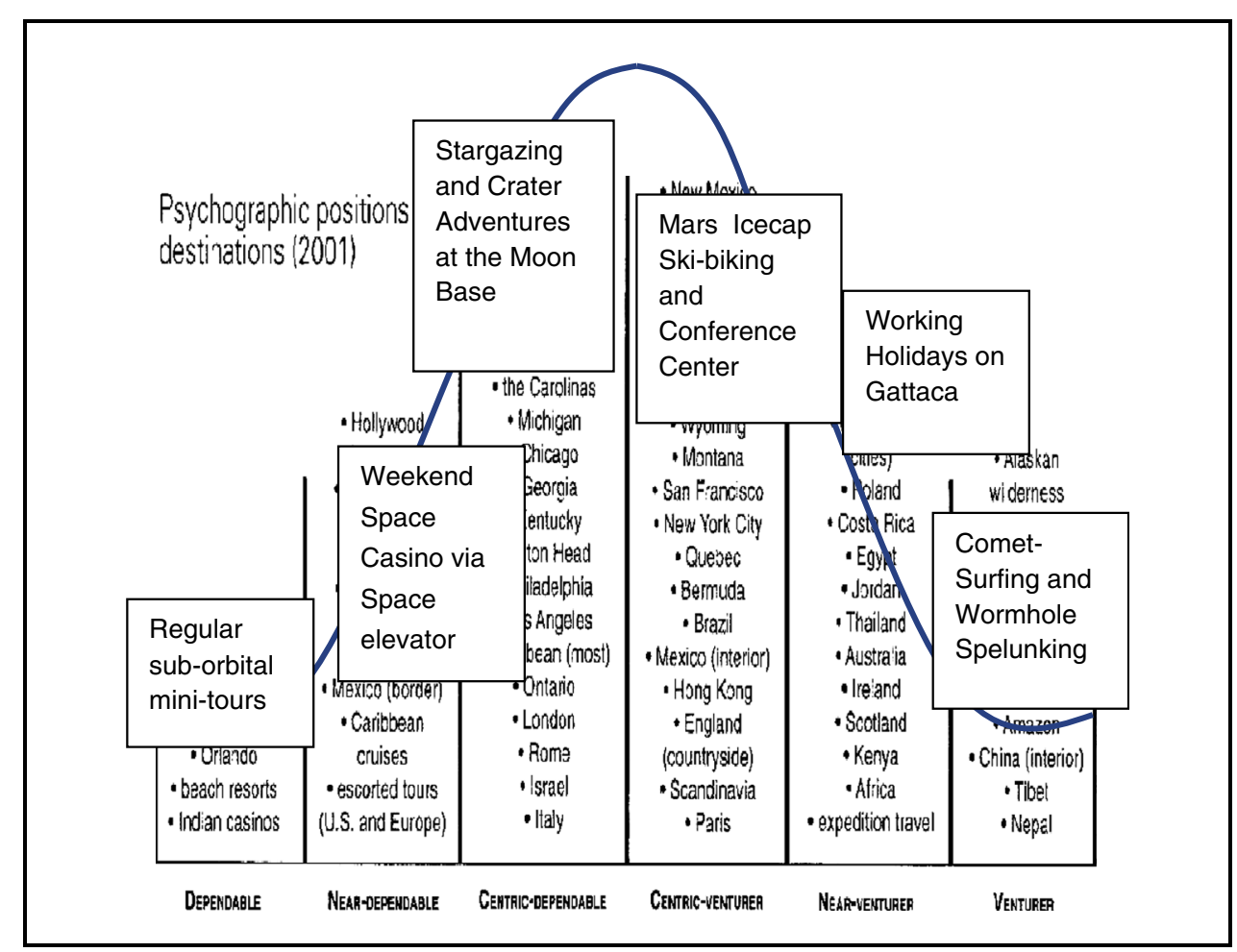

PAGE 134 | JOURNAL OF TOURISM FUTURES | VOL. 1 NO. 22015 


\section{The space destination life cycle}

Spacetourism.com explains that "Like any other business, once space tourism gets started it will develop progressively. It can be helpful to think of it as going through several phases. Starting with a relatively small-scale and relatively high-priced 'pioneering phase,' the scale of activity will grow and prices will fall as it matures. Finally it will become a mass-market business, like aviation today." This sequence is summarized in Table I.

The kind of service, volume of travelers, and expected price discussed are below. Segmentation of visitor markets and destinations, psychometric or otherwise, overlaps another core heuristic of the tourism literature, Butler's tourist area life cycle (TALC) that incorporates the ideas of Plog and others about the composition of a destination into the product life cycles theories associated with Vernon and others. Figure 2 shows the correspondence of these postulated phases of space tourism development when superimposed onto the "classic" Butler TALC. The first steps will be short sub-orbital flights, similar to the space-race flights of the 1960s. Whether "space" as a whole or "near earth-orbits" or individual hotels, lunar sites, and so on are defined

\section{Table I Phases of space tourism}

\begin{tabular}{|c|c|c|}
\hline Stage & Tourism product & Price and volume \\
\hline Pioneering & $\begin{array}{l}\text { The product will be nearer to adventure } \\
\text { travel than to luxury hotel-style. Orbital } \\
\text { accommodation will be safe but Spartan }\end{array}$ & $\begin{array}{l}\text { Customers will be relatively few - from } \\
\text { hundreds to thousands per year; prices } \\
\text { will be high, } \$ 50,000 \text { and up }\end{array}$ \\
\hline Mature & $\begin{array}{l}\text { This will see demand growing and flights } \\
\text { will depart from many different airports }\end{array}$ & $\begin{array}{l}\text { Tickets to orbit will cost less with } \\
\text { thousands to hundreds of thousands } \\
\text { passengers per year }\end{array}$ \\
\hline Mass & $\begin{array}{l}\text { Orbital facilities will grow from being just } \\
\text { clusters of pre-fabricated modules to large } \\
\text { orbiting structures for hundreds of guests } \\
\text { with a range of orbital entertainments }\end{array}$ & $\begin{array}{l}\text { Ticket prices will fall to the equivalent of a } \\
\text { few thousand dollars with now hundreds } \\
\text { of thousands to millions of passengers } \\
\text { per year }\end{array}$ \\
\hline
\end{tabular}

Figure 2 The tourist area life cycle in space

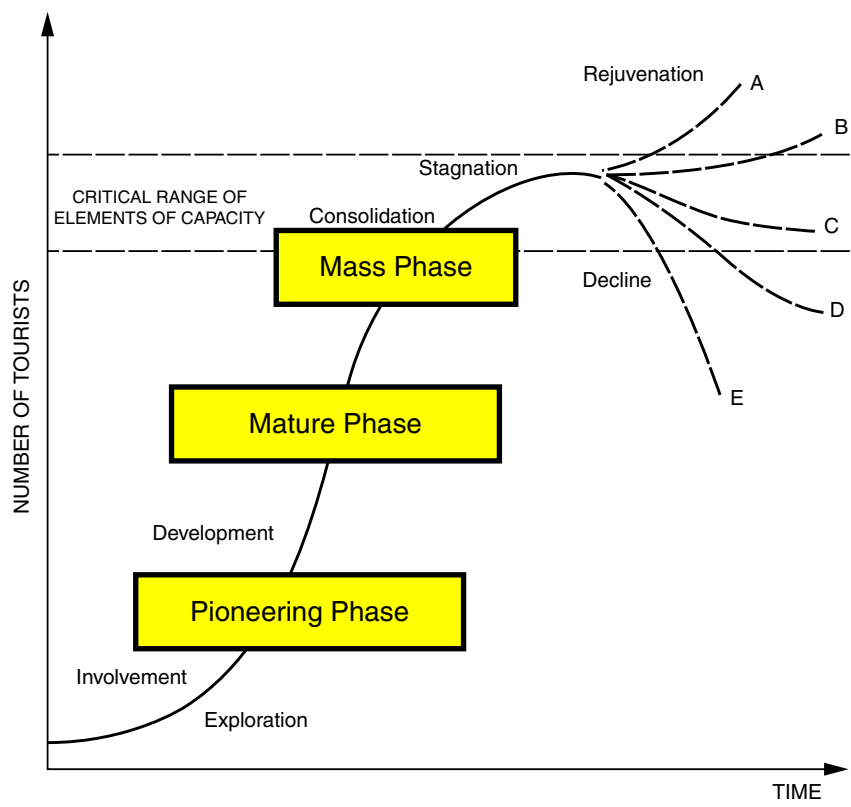


as the "tourist area," the issue here (as with destinations on Earth) is the capacity of the destination and associated constraints and technologies.

This pioneering stage is closer to a nineteenth century Grand Tour, early balloonists or trans-Atlantic airships, or a 1960s Hippie Trail. The next phase will see a maturing equivalent to the jet aircraft age. And as with most new technologies the initial stages are plagued by delays. The more important later stages of the TALC embody the ideas of congestion, sustainability, and the like. Given the volume of visitors anticipated, many space destinations - orbital, or moon-based, or otherwise off-worldly, are likely to become "over-crowded." Just as with the multitude of potent island and wilderness sites scattered across the globe, it is a fact that for reasons of scale economies, history, familiarity, marketing, herd-instinct among investors and travelers, that destinations and resorts have become "overcrowded," usually implying a considerable deterioration of the original attractions.

Spacetourism.com remarks that it is "Apparently unthinkable to most people in the space industry, even 1 million passengers per year is just 8 [presumably million] hours of aviation!" There's certainly no limit to the possible destinations. "And the access to space resources that low cost launch will bring about will ensure that economic growth needn't end for a few more millennia at least!" Whilst it might not be implausible to explore the implications of rapid growth of space tourism in total, or even at the sub-orbital, orbital, moon-based, and inter-planetary levels, every individual destination will likely face their own issues of capacity and congestion that underlie thinking about the tourist-destination lifecycle. Thus, as with the projections of UNWTO and other agencies, one might give pause when exponentially extrapolated global trends are used to promote tourism at the destination level (see e.g. Cole and Razak, 2009).

Indeed, the future of space tourism with unlimited growth might be as some consider that we simply "mess up and move on" into an increasingly-infinity of accessible destinations and spaces. There certain has to be some slowdown in the rate of increase - if the exponential growth period is extended then the annual number of passengers would eventually exceed the expected population of Earth. Of course, by then, travelers may make multiple trips and sub-orbital flight may be the primary mode of inter-continental travel, and business people may travel regularly to corporate subsidiaries on the Moon and wealthier tourists may have purchased timeshare, fractional ownership, and recreational homes, and the AirBnB.com web site graduated to SpaceBnB.com

Presumably, too, in the more distant future with more permanent colonies and dedicated off-earth tourism destinations, there will be similar confrontations as portrayed in several science fiction movies. The point here is not to Cassandra humankinds' potentially greatest-ever endeavor, but to point out that there are many lessons to be incorporated into thinking about future space-tourism from many tourist-destination experiences, past and present.

\section{Space travel for all?}

An article on Spacetourism.com (from the 1999 50th International Astronautical Congress in Amsterdam) says that "According to current reports in the media, traveling to outer space should become possible for everyone by the beginning of the next century. Developing low-cost passenger launch vehicles is not just to create an expensive pastime for the wealthy but develop a large 'middle-class' market rich. Indeed, until access to space is cheap, it will not be possible to make use of the limitless resources available in space to solve the problems of our ever-more-crowded Earth. And here it is argued that tourism can generate the large-scale launch activity needed to reduce costs sufficiently to start to use space resources. Hence, this is "one of the most important projects in the world today." Collins (2014) projects that, by 2100 , there could be annually 30 million sub-orbital, 40 million orbital, and 10 million lunar surface travelers.

As with many business plans and proposals, it is especially tricky to evaluate and compare the various costings, forecasts, and marketing models. But as with any new technology, including hotel, travel, and entertainment enterprises, there are price reductions as the technology 
matures, and the scale of operations, operators, and markets increase. Over the last decade the precise costs have varied, but whether this is because of modified vehicle techniques and spaceport location, discount rates and margins, products and market appraisal, is not always clear. That said, there are differences in products and prices - although even these, on review, raise further questions.

Table II compares the estimated price and duration of the flight and weightlessness times associated with each of the soon-to-be introduced sub-orbital offerings of Virgin and Lynx. (A full-length video comparing the Lynx and Galactic is found at www.parabolicarc.com/2011/ 08/24/). The trade-off for travelers in terms of "value for money" in terms or exclusivity and experience are not as clear cut as generally perceived. Luxurious pre-flight offerings are similar: "After two or three fabulous days of preparing with your crew - you're suited up and you're raring to go." But, while both offer a unique experience they may also be a very expensive one-off thrill. They compete with skiing, mountain biking, scuba diving, hang gliding, base jumping, rock-climbing, and the ever-increasing plethora of activities for committed excitement seekers. All might be considered better value for money.

As Collins observes, the potentially huge market for space tourism "gives huge scope for reducing the cost of space travel by large-scale operation like airlines." There are a variety of scale economies in number of passengers per flight and number of flights per year: for example, once the technologies reach maturity the costs fall drastically, For example, a cost comparison between the Sänger launcher as "developed to airliner maturity" and a Boeing 747, indicated that the cost per seat to orbit is about 1,000 times less than that of the Space Shuttle. Of course, this may be a dubious comparison. There are also similar scale economies from the number of operations and flights. Table I illustrates the enormous potential "chicken and egg" feedbacks between the number of space travelers and the cost per trip.

Collins explains that at the same time that the cost of each version of space tourism becomes less expensive the experience will be extended (in both distance and duration) and trips will become more costly. Collins (2014) indicates that by the 2020s a sub-orbital ride will cost $\$ N, 000$, by the 2030s (with " $N$ " being a number between 1 and 9), an orbital trip will cost $\$ N 0,000$, and in the 2040s a lunar ride will cost $\$ N 0,000$, about the same as sub-orbital rise today. A rough estimate of price per mile is $\$ 20(\$ 2 \mathrm{~K} / 100)$, 40cents $(\$ 20 \mathrm{~K} / 50 \mathrm{~K})$, and 20 cents $(\$ 200 \mathrm{~K} / 1 \mathrm{~m})$, a factor of 100 in 20 years (comparable to Moore's Law for the increasing speed and declining cost of computing power). Table III shows that there are substantial cost-reductions in moving from small (20 passenger) two- to single-stage reusable space vehicles, with less advantage trebling capacity from 60 to 180 seats. Indeed, the smaller craft appears to offer a slight advantage. It should be noted that the "costs" here are that for operating vehicles, rather than price to space tourists, and the prices quoted earlier indicate a healthy mark-up reflecting risk investment, insurance, and so on. Similarly, there appears to be rather smaller advantage in multiple launch sites, at least for smaller craft, which suggests that several independent commercial enterprises might co-exist, at least in the initial phase of space tourism.

Table II Cost versus value in space travel

\begin{tabular}{lrr} 
& Virgin Galactic & Xcor Lynx \\
\hline Original planned start date & 2013 & 2014 \\
Passengers & 6 & 1 \\
Max altitude km & 110 & 103 \\
Vacation/preparation days & 3 & 3 \\
Airtime min. & 150 & 30 \\
Weightless min. & 6 & 4.6 \\
Price \$000s & 200 & 95 \\
Cost/airtime min. \$000s & 1 & 3 \\
Cost/weightless min. \$000s & 33 & 21 \\
Cost/night \$000s & $\sim 66$ & $\sim 32$
\end{tabular}


Table III Scale economies in the size and number of spaceports and vehicles

Two stage reusable two stage reusable

Passengers

Max. no. passengers per year

No. Launch sites

Max. no. launches/site/year

No. flights before replace

$R \& D$ costs $\$ b n$

Infrastructure costs \$bn

Total costs \$bn

Min. operating costs/flight \$m

Cost/Passenger $\$$

Based on Collins

$20-20$

20

2,000

2

50

250

1.5

0.4

1.9

1.38

69,000

20
120,000
18
355
500
3.0
2.0
5.0
1.25
62,500

62,500
Single stage reusable single stage reusable

$\begin{array}{rr}60 & 180 \\ 360,000 & 1,000,000 \\ 18 & 18 \\ 355 & 355 \\ 500 & 500 \\ 3.9 & 4.6 \\ 2.2 & 3.0 \\ 6.1 & 7.6 \\ 0.97 & 3.30 \\ 16,167 & 18,333\end{array}$

The information in Table II allows various dimensions of the "value" of space flights to travelers to be scored. The overall cost with Virgin is double that of Xcor but since the flight time and weightless flight times are Virgin is cheaper in terms of cost per minute, but more expensive in terms of cost per weightless-minute. Xcor is also cheaper in terms of cost per day and the Curacao operation extolls the advantage of its Caribbean location. On the other hand, the Virgin flight can be shared by honeymoon couples.

\section{Multipliers in space}

One of the more important concepts in tourism planning is that of the "multiplier." Precisely which type of multiplier is most relevant, income, jobs, revenue, land footprint depend on the issue at hand; but in each case what matters is the net contribution of a tourist activity to the local community. With most international tourism there is a very high leakage of income, so only a small proportion of tourist spending is circulated within the local economy. Nonetheless, many sophisticated destinations focus on maximizing total tourist (and notably REVPAR) spending rather than the net impact on their population (product of the retained revenue and the appropriate multiplier).

For localities hosting the launch site, the main goal, in terms of its economic development, must be to generate jobs, income, and revenues. Unlike land-based destinations where, from a development planning perspective, the goal is to use tourism to drive the local economy through the creation of jobs, building on local skills, culture, and ecology. This is especially difficult when enormous international commercial enterprises are involved, as is inevitably the case with the infrastructure and operation of space tourism. The model for conceptualizing space tourism development might be a "Disney World" in the case of the Nevada launch-site of Virgin's Galactic, or a busy cruise port such as the Grand Bahamas for aspiring space-tourism launch sites islands such as Curacao and Puerto Rico. For earth-based space ports, it may be that a three-day stay at a tax-exempt all-inclusive and exclusive spa resort is the better starting point for considering the local economic impacts on employment and revenues.

In contrast, a cruise ship analogy may be the appropriate starting point for assessing the impacts of space flight and accommodations: SpaceFuture.com observes that "Most cruise ships are owned by off-shore companies operating out of countries with beneficial tax and regulatory regimes such as the Bahamas". Thus, the mammoth cruise ship analogy also illustrate the eventual scale and operation of space hotels with an ever expanding variety of concessions, entertainment and activities, even sports stadia and theme parks.

As with cruise lines, space hotel operators will also try to minimize the taxes and deflect constraining legislation with corresponding income allocation and impacts. Figure 3 characterizes the likely income flows from space tourism showing the various leakages and circulation of income between investors, space tourists, space ports and their host communities, and space resorts (the density of line indicates the relative scale of income flows). 
Spaceport Expenditures and Multipliers

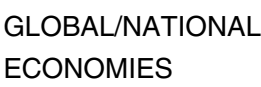

ECONOMIES

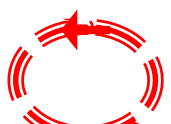

Traveler and

Investor

Expenditures

Spaceport

Amenities

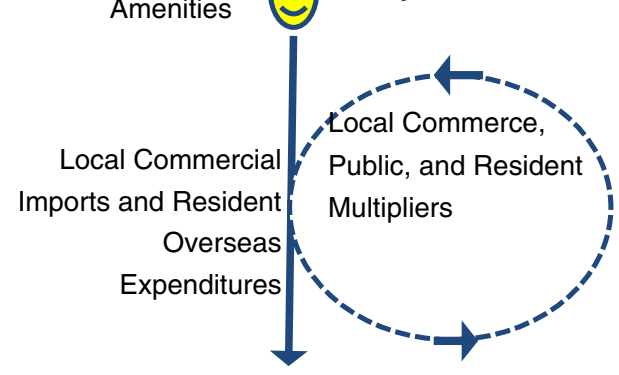

Space Tourism Enterprise

Overseas and Space

Purchases and Income

Repatriation

Eventually off-planet space destinations will become "communities" with temporary and semipermanent residents living in company towns with their own local electronic currency and administration. Beyond this, new space island cultures will arise in migratory settlements, leading to their own unilateral declarations of independence.

Meanwhile, back on Earth, it is not implausible that major new economic regions based on the manufacture of spacecraft, supporting infrastructure, and launch sites will emerge. Indeed, it is not difficult to concur with Collins and others cited in this paper that space tourism could become a new driver for global development, and ultimately for human development beyond our planet and solar system. A short survey of students in the tourism class indicated that they share this view and they too have ambitions to travel in space (see Table IV).

\section{Table IV Students in space}

Question

Average response

Would you travel on the first space-tourism trip if it was free

Do you see human futures in space

Are there non-human intelligent beings

Would you take a vacation in Space

Would you migrate to a permanently space colony

Will we meet space aliens

Have recent events caused you to change your mind ${ }^{b}$

How much would you pay

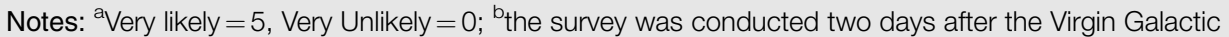
disaster 


\section{Postscript}

The very week this paper was completed saw two spacecraft disasters: a launch failure of an unmanned Antares space station delivery rocket and the more tragic Virgin Galactic Spaceship II test flight. The second especially potentially poses a significant setback for space tourism.

\section{References}

Butler, R. (1980), "The concept of a tourist area cycle of evolution: implications for management of resources", Canadian Geographer, Vol. 24 No. 1, pp. 5-12.

Cole, S. and Razak, V. (2009), "Tourism as Future", Futures, Vol. 41, pp. 335-45.

Collins, P. (2000), "How space tourism can help solving Italy's crisis", Congress of Space Proceedings of Space 2000, Presented at Space 2000, ASCE, Albuquerque, March, pp. 594-603, available at: www.youtube.com/watch?v=iJ9dhMoKVi4

Collins, P. (2014), "Renaissance Italia", held at the Politecnico di Milano, Campus Bovisa, May 8-9.

Plog, S. (2001), "Why destination areas rise and fall in popularity", The Cornell Hotel and Restaurant Administration Quarterly, Vol. 42 No. 3, pp. 55-8.

\section{Corresponding author}

Professor Sam Cole can be contacted at: samcole@buffalo.edu 